NASA/TM-2012-217428

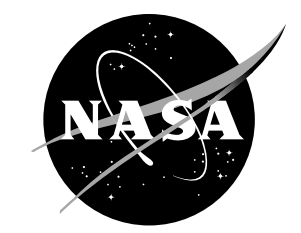

\title{
Multi-Objective Optimization of a Turbofan for an Advanced, Single-Aisle Transport
}

Jeffrey J. Berton

Glenn Research Center, Cleveland, Ohio

Mark D. Guynn

Langley Research Center, Hampton, Virginia 


\section{NASA STI Program . . . in Profile}

Since its founding, NASA has been dedicated to the advancement of aeronautics and space science. The NASA Scientific and Technical Information (STI) program plays a key part in helping NASA maintain this important role.

The NASA STI Program operates under the auspices of the Agency Chief Information Officer. It collects, organizes, provides for archiving, and disseminates NASA's STI. The NASA STI program provides access to the NASA Aeronautics and Space Database and its public interface, the NASA Technical Reports Server, thus providing one of the largest collections of aeronautical and space science STI in the world. Results are published in both non-NASA channels and by NASA in the NASA STI Report Series, which includes the following report types:

- TECHNICAL PUBLICATION. Reports of completed research or a major significant phase of research that present the results of NASA programs and include extensive data or theoretical analysis. Includes compilations of significant scientific and technical data and information deemed to be of continuing reference value. NASA counterpart of peer-reviewed formal professional papers but has less stringent limitations on manuscript length and extent of graphic presentations.

- TECHNICAL MEMORANDUM. Scientific and technical findings that are preliminary or of specialized interest, e.g., quick release reports, working papers, and bibliographies that contain minimal annotation. Does not contain extensive analysis.

- CONTRACTOR REPORT. Scientific and technical findings by NASA-sponsored contractors and grantees.
- CONFERENCE PUBLICATION. Collected papers from scientific and technical conferences, symposia, seminars, or other meetings sponsored or cosponsored by NASA.

- SPECIAL PUBLICATION. Scientific, technical, or historical information from NASA programs, projects, and missions, often concerned with subjects having substantial public interest.

- TECHNICAL TRANSLATION. Englishlanguage translations of foreign scientific and technical material pertinent to NASA's mission.

Specialized services also include creating custom thesauri, building customized databases, organizing and publishing research results.

For more information about the NASA STI program, see the following:

- Access the NASA STI program home page at http://www.sti.nasa.gov

- E-mail your question via the Internet to help@ sti.nasa.gov

- Fax your question to the NASA STI Help Desk at $443-757-5803$

- Telephone the NASA STI Help Desk at 443-757-5802

- Write to: NASA Center for AeroSpace Information (CASI) 7115 Standard Drive Hanover, MD 21076-1320 
NASA/TM-2012-217428

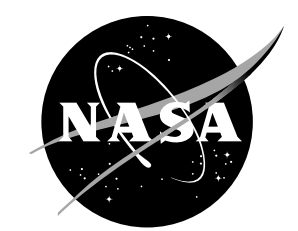

\section{Multi-Objective Optimization of a Turbofan for an Advanced, Single-Aisle Transport}

Jeffrey J. Berton

Glenn Research Center, Cleveland, Ohio

Mark D. Guynn

Langley Research Center, Hampton, Virginia

National Aeronautics and

Space Administration

Glenn Research Center

Cleveland, Ohio 44135 


\section{Acknowledgments}

We would like to thank the other members of the NASA Intercenter Systems Analysis Team who worked on the initial ultra-high bypass ratio engine study that preceded this analysis. William Haller, Douglas Thurman, Kenneth Fisher, and Michael Tong, your work is appreciated. We would also like to thank the Subsonic Fixed Wing Project of

NASA's Fundamental Aeronautics Program for supporting this effort.

This report is a formal draft or working paper, intended to solicit comments and ideas from a technical peer group.

This report contains preliminary findings, subject to revision as analysis proceeds.

Trade names and trademarks are used in this report for identification only. Their usage does not constitute an official endorsement, either expressed or implied, by the National Aeronautics and Space Administration.

This work was sponsored by the Fundamental Aeronautics Program at the NASA Glenn Research Center.

Level of Review: This material has been technically reviewed by technical management.

Available from

NASA Center for Aerospace Information 7115 Standard Drive

Hanover, MD 21076-1320
National Technical Information Service 5301 Shawnee Road Alexandria, VA 22312 


\title{
Multi-Objective Optimization of a Turbofan for an Advanced, Single-Aisle Transport
}

\author{
Jeffrey J. Berton \\ National Aeronautics and Space Administration \\ Glenn Research Center \\ Cleveland, Ohio 44135 \\ Mark D. Guynn \\ National Aeronautics and Space Administration \\ Langley Research Center \\ Hampton, Virginia 23681
}

\begin{abstract}
Considerable interest surrounds the design of the next generation of single-aisle commercial transports in the Boeing 737 and Airbus A320 class. Aircraft designers will depend on advanced, nextgeneration turbofan engines to power these airplanes. The focus of this study is to apply single- and multiobjective optimization algorithms to the conceptual design of ultrahigh bypass turbofan engines for this class of aircraft, using NASA's Subsonic Fixed Wing Project metrics as multidisciplinary objectives for optimization. The independent design variables investigated include three continuous variables: sea level static thrust, wing reference area, and aerodynamic design point fan pressure ratio, and four discrete variables: overall pressure ratio, fan drive system architecture (i.e., direct- or gear-driven), bypass nozzle architecture (i.e., fixed- or variable geometry), and the high- and low-pressure compressor work split. Ramp weight, fuel burn, noise, and emissions are the parameters treated as dependent objective functions. These optimized solutions provide insight to the ultrahigh bypass engine design process and provide information to NASA program management to help guide its technology development efforts.
\end{abstract}

\subsection{Introduction}

NASA sets aggressive, strategic, civil aircraft performance and environmental goals and develops ambitious technology roadmaps to guide its technology research efforts. Under NASA's Fundamental Aeronautics Program, the Subsonic Fixed Wing Project has adopted fuel efficiency, community noise, exhaust emissions, and takeoff field length goals for the new, subsonic, single-aisle, civil aircraft expected to replace the current Boeing 737 and Airbus A320 families of airplanes. Relative to B737-800/CFM567B performance levels, NASA goals call for 33\% reductions in block fuel burn and takeoff field length. The NASA goal for oxides of nitrogen $\left(\mathrm{NO}_{\mathrm{X}}\right)$ is $60 \%$ below the landing and takeoff emission stringencies set in 2004 by the Committee on Aviation Environmental Protection (CAEP/6) (Ref. 1). Additionally, these aircraft are to achieve certification noise levels 32 cumulative EPNdB under current FAA stage 4 (Ref. 2)/ICAO chapter 4 noise limits (Ref. 3).

Since these performance metrics are aggressive and often conflicting, achieving goal levels for the fuel burn, noise, emissions, and field length metrics simultaneously may not be possible. These goals therefore may represent distinct "corners" of the airplane design trade space. A balanced, profitable business-case airplane design may satisfy one or more of these goals, but is unlikely to meet the goal of every metric at once.

The multidisciplinary design and analysis of an advanced, single-aisle civil airplane lends itself well to single- and multi-objective optimization. In this study, the NASA goal metrics for performance, noise, and emissions serve as the basis for this practical optimization problem with important implications for the product's design and expectations. 
This assessment leverages tools, methods, and results from earlier NASA system concept studies conducted in 2008 and 2009, in which ultrahigh bypass (UHB) turbofan engines were examined for a notional, single-aisle transport (Refs. 4 to 6). A parallel acoustics study of the airplane was also performed (Ref. 7). The objective of the NASA UHB engine concept studies was to determine if the fuel consumption and noise benefits of engines having lower fan pressure ratios (and correspondingly higher bypass ratios) translate into overall aircraft system-level benefits for a 737-class vehicle. Such information is important to help NASA program management guide its own technology development efforts.

In References 4 to 6, the propulsion system conceptual design trade space was examined by designing a representative family of 48 UHB engines, analytically installing them on a common airframe model, and performing aircraft mission performance and sizing analyses. The independent propulsion design variables investigated were aerodynamic design point fan pressure ratio, overall pressure ratio, fan drive system architecture (i.e., direct- or gear-driven), bypass nozzle architecture (i.e., fixed- or variablegeometry), high- and low-pressure compressor compression work split, and cruise Mach number.

In this study, all of the above design variables (except for the design cruise Mach number) are treated as design variables subject to optimization. Analytic computations of aircraft performance characteristics, including the NASA Project metrics (fuel burn, $\mathrm{NO}_{\mathrm{X}}$ emissions and noise) as well as ramp weight are the objective functions.

Significant fuel and cost reductions are necessary to justify the development of a new, single-aisle transport, or to justify retrofitting current aircraft with new engines. Substantial reductions in noise and emissions are required to enable unconstrained aviation growth without negatively impacting the environment. The expectation of this analysis is to broaden the solutions obtained during the studies of References 4 to 6 with the additional objectives of fuel, noise, and exhaust emissions included in the optimization. This single- and multi-objective optimization provides insight to the engine design options that will be necessary to achieve multiple goals.

\subsection{Nomenclature}

$D_{L} \quad$ landing field length

$D_{T O} \quad$ takeoff field length

$f_{\mathrm{i}} \quad$ optimization objective functions

$F_{N, S L S} \quad$ sea level static thrust

$g_{\mathrm{i}} \quad$ optimization inequality design constraints

$h_{\text {pot,toc }} \quad$ potential rate of climb at top of climb conditions

$N M_{\text {Cum }} \quad$ cumulative noise margin relative to the stage 4/chapter 4 rule

$N O_{X} \quad$ oxides of nitrogen (nitric oxide and nitrogen dioxide) exhaust emissions

$S_{W} \quad$ reference trapezoidal wing area

$x_{\mathrm{i}} \quad$ optimization design variables

$v_{a p p} \quad$ approach velocity

$W_{\text {blockfuel }} \quad$ block fuel weight

$W_{\text {ramp }} \quad$ ramp weight

$\Delta F_{N, \text { mapp }} \quad$ missed approach excess net thrust

$\Delta F_{N, s s} \quad$ second segment climb excess net thrust

$\Delta W_{\text {excess fuel }}$ excess fuel weight 


\subsection{Method of Analysis}

Once expected to enter service as early as 2015, it now appears a new single-aisle aircraft in the 150 -seat class will be delayed for several more years. Airbus has elected to proceed with an engine retrofit program with their A320neo. And as of this writing, Boeing may yet proceed with a 737 engine retrofit program of their own rather than design a new, "clean sheet" airplane. Nonetheless, a notional airplane intended to represent an all-new, 737 replacement equipped with new UHB turbofans is modeled here. Engine component and subsystem performance, hot section cooling levels, and material technologies appropriate for an approximate 2015-2020 service entry date are assumed. Airframe technologies commensurate with a 2015-2020 service entry date are also assumed.

The tools and procedures described in Reference 4 have essentially been automated so that the entire multidisciplinary analysis may be driven by single- and multi-objective optimizers. This is no small feat, as many heuristic design rules are added to remove the engineer from the loop without introducing errors.

Each disciplinary analysis is summarized below. Numerical accuracy and numerical solution errors for each analysis are very small and are insignificant relative to the uncertainties introduced by the assumptions made.

\subsection{Propulsion System}

The basic engine architecture is a boosted, two-spool, separate-flow turbofan. Three-spool engines represent another potentially viable turbofan architecture for this aircraft class, but they are not investigated here. The propulsion system independent design variables subject to optimization are the sea level static thrust, fan pressure ratio (FPR) at the aerodynamic design point (ADP), the overall pressure ratio (OPR) at the ADP, the fan drive system architecture (i.e., direct- or gear-driven), the bypass nozzle architecture (i.e., fixed- or variable-geometry), and the high- and low-pressure compressor compression work split.

A multiple design point analysis is performed on the engine cycle to meet several performance requirements such as airplane thrust demand, as well as to set flow rates, cycle temperatures, pressures, spool speeds, and cooling levels.

An advantage that a new, "clean sheet" airplane enjoys is that it may be designed to accommodate high-diameter nacelles. This is unlike an existing airplane undergoing an engine retrofit, where underwing clearance is limited and fan diameter must be constrained. To exploit this benefit, a multiple-point analysis is used to design each engine cycle to meet targets for thrust that the airplane requires at the end of the runway and at the top of its climb. In other words, the thrust lapse from takeoff to the top of climb is identical for every engine designed. In an analysis without a fan diameter constraint, engine airflow and the ratio of combustor temperatures from takeoff to top-of-climb may be varied to satisfy the airplane thrust demand. Of course, if the thrust lapse is held constant, other cycle parameters lapse instead. Perhaps most important of these is temperature. High-bypass cycles have higher hot section temperatures during cruise than lower bypass cycles, and thus a hot-section component life analysis would be necessary in a later design stage.

The cycle ADP reference is at the top-of-climb condition (Mach $0.80,35 \mathrm{kft}$, standard temperature), and the rolling takeoff condition is at sea level, Mach $0.25,86^{\circ} \mathrm{F} / 30^{\circ} \mathrm{C}$. Turbomachinery is represented by scaled component performance maps. Additional details on the engine design, material selections, and engine technology level assumptions may be found in References 4 to 6 .

The thermodynamic engine cycle performance is analyzed using the Numerical Propulsion System Simulation code (NPSS, Refs. 8 and 9). NPSS is a variable-fidelity, object-oriented, engine cycle analysis tool developed jointly by NASA and U.S. industry. It is currently the accepted, state-of-the-art software for airbreathing engine cycle performance analysis for U.S. aerospace industry, academia, and NASA. Aeromechanical design, flowpath, and engine weight analyses are performed with the Weight Analysis of Turbine Engines code (WATE, Ref. 10). WATE has been significantly upgraded since its initial 
introduction in the 1970s and is currently implemented as a suite of NPSS interpretive analysis elements. At NASA, WATE is coupled with NPSS to provide a complete modeling capability of turbofan engines.

The design FPR has a large influence over an engine's performance, dimensions, and weight. Its value, along with the ratio of pressure levels in the bypass and core exhaust ducts (the extraction ratio), sets the bypass ratio - a major determinant of an engine's fuel consumption characteristics. Bypass ratio is inversely proportional to FPR; as FPR is reduced, fan airflow must increase to maintain thrust requirements. Constant design fan loading is assumed in this analysis, therefore the choice of FPR sets the fan tip speed and the rotation rate of the low-pressure spool. FPR is also a major consideration in setting the design airflow; thus, it factors into the overall diameter, weight, wetted area, and drag of the propulsion system. The choice of FPR also has a considerable effect on the low-pressure turbine design, particularly in cases where no fan gearbox is present. It is selected as a design variable for the optimization. The range of values considered is 1.35 to 1.70 ; these are approximate practical limits for large, single-stage fans.

The design OPR also has a large influence over cycle performance, with higher OPRs providing the benefits of higher engine thermal efficiencies. It also has implications in exhaust $\mathrm{NO}_{\mathrm{X}}$ emissions, as discussed below. Treating OPR as another continuous design variable, however, leads to excessive computational time. Instead, it is treated here as a discrete variable with two options: a "high" value of 42 at the ADP and a "low" value of 32 at the ADP. An ADP OPR of 42 is the approximate upper limit for this type and class of engine. With reasonable compressor disk and compressor exit Mach number design assumptions, an OPR of 42 leads to compressor annular exit passage heights of approximately one-half inch (a typical limiting constraint used in axial turbomachinery design).

An engine design variable related to OPR is the compression work split between the high- and lowpressure compressors. For a given fan pressure ratio and overall pressure ratio, the "low work" engines have a lower pressure rise across the low-pressure compressor (and a correspondingly higher pressure rise across the high-pressure compressor) compared with the "high work" engines. For example, in engines having an ADP OPR of 42, the high-pressure compressor pressure ratio is 17.7 for the "low work" designs, but it is only 12.0 for the "high work" designs. The low-pressure compressor pressure ratio is selected to produce the desired OPR as FPR varies. The compression work split is also represented as a two-valued discrete design variable, rather than by a continuous real variable. More information on how the work split logic is implemented may be found in References 4 to 6 .

Low FPR engine cycles generally require some type of variable geometry for proper operation throughout the flight envelope. Without variable geometry, a sufficiently low ADP FPR at altitude will lead to a fan surge problem when operating near sea level. The most attractive way to solve this problem may be with a variable-geometry bypass nozzle. The nozzle exit opens when operating near sea level, and the resulting increase in flow area shifts the fan operating point away from the surge line. The variablegeometry nozzles in the analysis are assessed a $10 \%$ weight penalty relative to equivalent fixed-geometry designs. The exit areas of the variable nozzles are varied at off-design using an NPSS solver balance to maintain a constant fan operating line. Engines equipped with variable-geometry nozzles therefore enjoy operation near peak fan efficiencies, albeit at the cost of added nozzle weight. Whenever the optimizer naively "creates" an engine by coupling a fixed-geometry nozzle with a low-pressure fan, the fan design surge margin is automatically increased by the optimizer's heuristic rule set so that the fan always operates with an adequate surge margin in off-design conditions. This results in the fan operating at very low fan efficiencies during cruise. In reality, a low-pressure fan would never be designed with a fixedgeometry nozzle, but it is possible in the analytical world. The punishing effects of a very high design fan surge margin should naturally cause the optimizer to avoid these designs.

The choice of the fan drive system architecture is a major propulsion design consideration. At reasonable fan loadings, a fan having a low design pressure ratio spins relatively slowly. Without a gearbox, the low-pressure turbine (LPT) must rotate at the same low speed. This sets up the classical shaft speed mismatch for two-spool turbofans having low design fan pressure ratios. The LPT diameter cannot simply be increased to maintain high, efficient tip speeds without weight penalties and without obstructing the flow in the bypass duct. The stage count of the LPT in a conventionally-driven turbofan 
must increase as the design FPR is reduced if reasonable LPT loadings are maintained, which adds considerable weight and length to the engine. Exacerbating the problem is the high gas temperatures in the hot section of the engine (relative to those in the fan), which effectively elevates the speed of sound and lowers the tip Mach numbers of the LPT. The shaft speed mismatch can be altogether avoided by using a gearbox, which enables the fan and the low-pressure spool to operate at different rotational speeds. Use of a gear system does, however, introduce a separate set of concerns such as gearbox weight, reliability, and cost. In this study, a binary discrete design variable determines if a fan gearbox is present. The optimizer will frequently (and naively) seek to combine a directly-driven fan with a low FPR. Such poorly-designed systems will have a large number of LPT stages (and low-pressure compressor stages, particularly in the case of the "high work" engines). But, like the situation discussed above with the variable-geometry bypass nozzle design switch, the resulting poor objective values should steer the optimizer away from these designs.

\subsection{Airplane}

It is not sufficient to determine aircraft benefits from engine characteristics alone. Improvements in fuel consumption, for example, often come at the expense of engine size and weight. Only by combining the engines with an airframe model can the net impact of an engine design be captured. Aircraft synthesis and sizing analyses are carried out using NASA's Flight Optimization System (FLOPS, v8.0, Ref. 11) computer program. The weights, dimensions and flight envelope performance of each propulsion system design described above are passed to FLOPS via tabular input files. FLOPS scales the engine and wing sizes to meet the airplane performance constraints described in Section 4.0. Special sizing considerations introduced by large, UHB engines with unconstrained fan diameters are addressed through enhancements to the FLOPS analysis. Spreadsheet analyses are used to determine landing gear length and weight, engine-out drag, and required vertical tail size so that impacts of large-diameter engines are properly captured. Enhancements to basic FLOPS capabilities are also made in the structural weight and aerodynamics areas. The wing and fuselage structural weight estimates of FLOPS are replaced with estimates from PDCYL (Ref. 12). PDCYL offers a less empirical, more analytical weight estimation methodology that is more sensitive to parameters such as engine weight and location. FLOPS aerodynamic predictions are enhanced through a model calibration process incorporating details of the 737-800 high-speed and low-speed aerodynamic performance.

\subsubsection{Baseline Airframe Model}

The notional airplane is based on an analytical evolution of the currently-in-service Boeing 737-800 with winglets. In Reference 4, a reference 737 analytical model was developed based on publiclyavailable 737-800 geometry, weight, and performance information; proprietary low-speed and cleanconfiguration aerodynamic data; and a NASA NPSS representation of the CFM56-7B engine. The CFM56-7B was analytically modeled in NPSS using data available from several public-domain sources, such as FAA type certification data sheets, manufacturer-provided operating documents, technical reports, Jane's Aero-Engines, and manufacturer's websites. No company-proprietary propulsion data were used. The reference 737 carries 162 passengers in a single-aisle, two-class seating arrangement. Minor calibrations to the FLOPS-computed component weights and aerodynamics were performed to match published operating empty weight and range capability of $3060 \mathrm{~nm}$ at a 32,400 $\mathrm{lb}$ payload. The FLOPS model was set up to perform a basic wing-engine sizing analysis. Scaling the wing and engine sizes of the reference model for minimum ramp weight subject to active aircraft performance constraints led to results that were consistent with the actual 737 aircraft. 


\subsubsection{Advanced Airframe Model}

To transform the reference 737 into the advanced vehicle model, the design cruise Mach number is increased from 0.785 to 0.800 , with an appropriate increase in wing quarterchord sweep (from 25 to $27^{\circ}$ ) to reflect the higher airspeed. The wing aspect ratio and taper ratio are unchanged. The 162-passenger, mixed-class, single-aisle cabin arrangement is maintained, but the design range at the $32,400 \mathrm{lb}$ payload point is increased from 3060 to $3250 \mathrm{~nm}$. The performance improvements in airspeed and range are considered appropriate for a future vehicle in this class.

Climb and descent flight segments are optimized to minimize time while respecting a calibrated airspeed limit of $150 \mathrm{kt}$ at altitudes less than 10,000 ft. An initial cruise altitude of $35,000 \mathrm{ft}$ is required. The cruise segment is a fixed Mach $(0.80)$, optimum-altitude climbing cruise which reflects the advanced air traffic management capabilities expected circa 2020.

Broad use of composite structural materials is assumed relative to the predominantly-metal construction of the 737 . This is comparable to the structure of the new Boeing 787 , where as much as $50 \%$ of the primary structure is made of composites. Composite construction of primary structures is assumed to result in a $15 \%$ reduction in the component weights computed for the wing, fuselage, and empennage. This weight reduction represents an assumed benefit for future composite structures and is not necessarily a claim for what has been achieved to date. Additional technology improvements similar to those found on the 787 include an increase in hydraulic pressure to $5000 \mathrm{psi}$ and an assumed $1 \%$ reduction in drag due to trailing edge variable camber and drag cleanup. A planform schematic of the vehicle is shown in Figure 1. This vehicle is the common airframe model for all of the propulsion systems analyzed.

\subsection{Takeoff and Landing Trajectory Analysis}

An important aspect of the aircraft-engine system not always considered in noise certification predictions is the influence of airplane trajectory and engine throttling on noise. UHB turbofans would have a lower specific thrust than a conventional or current turbofan; as a result, they have significantly different thrust characteristics. Even though the thrust lapse from takeoff to the top of the climb is identical for every engine designed, the thrust of UHB engines lapses more quickly in the takeoff regime as airspeed increases. To capture this difference, the throttle settings during the takeoff and approach trajectories require proper modeling to more appropriately predict certification noise values. Detailed takeoff and approach trajectory calculations are automatically made for every airplane and engine designed by the optimizer. These trajectory calculations are used to establish the field length of each airplane as well as for its certification noise levels.

Detailed, low-speed takeoff and landing assessments are made using FLOPS's built-in, time-stepping trajectory analysis module. Proprietary low-speed aerodynamic data for several flap and slat settings, thrust performance, and aircraft weights are inputs to the analysis. Compliance with the airworthiness requirements described in Part 25 (Ref. 13) and Part 36 (Ref. 2) of the Federal Aviation Regulations are observed. The low-speed trajectory analysis is validated for the baseline airframe model using performance data (Ref. 14) of a 737 taking off and landing under standard day, dry runway conditions. Takeoff and landing distances for the baseline airframe model match to within approximately $1 \%$ of the reported values. The same analysis is used to predict the trajectories of the advanced airframe model. 
A noise abatement throttle cutback occurs in all cases between 16,000 and 17,000 ft from brake release. The engine climb thrust at this distance is reduced to the minimum level permitted by regulation (i.e., Ref. 2 requires a minimum climb gradient of $4 \%$ with both engines operating, or level flight with one engine inoperative.). The power cutback typically takes place at approximately $1200 \mathrm{ft}$ above field elevation, depending on the characteristics of the engine and airplane designed by the optimizer. This is always above the minimum altitude permitted (i.e., $300 \mathrm{~m} / 984 \mathrm{ft}$ for a twinjet), in an attempt to gain additional altitude and reduce the noise at the flyover noise measurement point (located at $6500 \mathrm{~m} / 21,325 \mathrm{ft}$ from brake release). Because of its lower specific thrust relative to the CFM56-7B, a throttle cutback for a UHB engine designed to meet a rolling takeoff thrust target is typically not as deep (in percent thrust), and a typical UHB-powered airplane does not climb as high over the flyover measurement point as the 737 reference model does. These thrust-related effects have an impact on flyover noise and their impact should be captured. Likewise, the UHB engine throttle setting on the $3^{\circ}$ glide slope approach is typically higher than the CFM56-7B (in percent thrust). This also has an impact on the approach noise that should be taken into account. This analysis captures all of these trajectoryrelated effects on noise.

\subsection{Exhaust Emissions}

Oxides of nitrogen pose a health hazard to animal and plant life and are a potential ozone destruction risk in the stratosphere. In gas turbine engines, they are predominantly produced thermally via the Zeldovich chain reaction when ordinary nitrogen in the air comes into contact with high-temperature regions inside the combustor. There, nitrogen oxidizes into nitric oxide (NO), and much of it subsequently oxidizes further into nitrogen dioxide $\left(\mathrm{NO}_{2}\right)$, which are collectively known as $\mathrm{NO}_{\mathrm{X}} \cdot \mathrm{NO}_{\mathrm{X}}$ is one of the commercial jet engine exhaust emittants regulated by international standards (Refs. 15 and 16). The landing and takeoff (LTO) cycle defined in these regulations is intended to represent a single airplane operational cycle near airports. This cycle consists of four operational segments, each having a different throttle setting. The parameter regulated, LTO $\mathrm{NO}_{\mathrm{X}}$, is the amount of $\mathrm{NO}_{\mathrm{X}}$ (in grams) per kilonewton of maximum takeoff rated sea level thrust over the four segments of the operational cycle. LTO $\mathrm{NO}_{\mathrm{X}}$ is one of the objectives in this study.

Empirical correlation models are often used in conceptual design studies to predict an engine's $\mathrm{NO}_{\mathrm{X}}$ emission index $\left(\mathrm{EINO}_{\mathrm{X}}\right.$, defined as masses of $\mathrm{NO}_{\mathrm{X}}$ emitted per thousand masses of fuel burned). $\mathrm{EINO}_{\mathrm{X}}$ values are then used to make LTO $\mathrm{NO}_{\mathrm{X}}$ certification predictions. In this study, a correlation model developed during NASA's Ultra-Efficient Engine Technology Project is used to predict EINO $_{\mathrm{X}}$. The model is a strong function of combustor average reaction temperature, represented in the correlation by the fuel-air ratio. But, significant increases in NO have also been observed to be a function of combustor entrance temperature (Ref. 17) and, to a lesser extent, combustor entrance pressure (Refs. 18 and 19). Therefore, the correlation is also a function of combustor entrance total temperature and total pressure. Each of these properties are predicted by NPSS as noted above. Other constants in the correlation model are calibrated to represent next-generation combustor emissions technology levels and are fixed.

Most of the LTO $\mathrm{NO}_{\mathrm{X}}$ is produced during the two cycle segments having the highest thrust settings, when the combustor reaction temperatures are highest. The combustor temperature during maximum takeoff rated conditions is fixed across the engine design space and is limited by hot section materials constraints. Therefore, changes in combustor entrance conditions bring about the largest changes in LTO $\mathrm{NO}_{\mathrm{X}}$. The discrete design variable OPR $\mathrm{ADP}_{\mathrm{A}}$ will be shown to have a large influence on LTO $\mathrm{NO}_{\mathrm{X}}$.

LTO $\mathrm{NO}_{\mathrm{X}}$ is entirely independent of any airplane characteristic (indeed, in certification, it is measured on an engine test stand). To the first order, even the influence of engine size is removed from the metric via normalization by thrust. It is linked in this study to airplane-related metrics (such as airplane ramp weight) only by way of our multi-objective system optimization. 


\subsection{Certification Noise}

The certification noise analysis approach, assumptions, and tools used in this study have been examined by acoustics experts from NASA Glenn, NASA Langley, U.S. industry, and academia as part of a comprehensive, multifidelity, NASA acoustic tool benchmarking activity (Ref. 20). The Aircraft Noise Prediction Program (ANOPP, Release Level 27 (Refs. 21 and 22)) is a systems-level code used in this study to compute certification noise for the airplanes. The certification noise predictions of the reference 737 described in Reference 20 serve as a validation of the methods and tools used in this vehicle study.

Freefield, lossless, one-third-octave band frequency component source noise levels are computed using predictive modules within ANOPP. The UHB engine's thermodynamic, aeromechanical, and geometry data are used as inputs to ANOPP's propulsion source noise prediction methods. At NASA, the NPSS and WATE airbreathing component element libraries have functions, viewers, and case files coded in interpretive language to produce engine data to be used as ANOPP input parameters. These so-called "engine state tables" are the preferred method to transfer engine state data to ANOPP's source noise prediction modules. Engine state data, consisting of pressure, temperature, flow area, spool speed, and fuel and air flow rates, are computed by NPSS for a range of airspeeds, altitudes, and throttle settings at standard acoustic day $\left(77^{\circ} \mathrm{F} / 25^{\circ} \mathrm{C}\right)$ conditions. As the airplane traverses its flight path, engine data at the appropriate airspeed, altitude, atmospheric conditions, and throttle setting are interpolated from the state tables and are delivered to the source noise prediction modules.

The UHB engine's hardwall fan, jet, and core noise sources are predicted using ANOPP's Heidmann (Ref. 23), Stone et al. (Ref. 24), and Emmerling et al. (Refs. 25 and 26) methods, respectively. Propulsion noise reduction technologies applied in this analysis include nozzle chevrons, conventional doubledegree-of-freedom fan acoustic liners, soft vane stators (Ref. 27), and over-the-rotor foam metal treatment (Ref. 28). The latter two fan noise reduction technologies are anticipated to have matured enough for incorporation in the UHB engine assumed in this study. These technologies are also assumed to be relatively lightweight, inexpensive, low-maintenance, and free of aerodynamic performance penalties such that an engine manufacturer would be willing to make use of them on their product. In engine designs equipped with variable-area bypass nozzles, chevrons are assumed present for the central core nozzle only (chevrons are not applied to the bypass nozzle due to potential conflict with the actuation system needed for the nozzle design).

Freefield, lossless, one-third-octave band spectra for flap, slat, landing gear, and trailing edge airframe noise sources are predicted using a method developed by M.R. Fink for the FAA (Ref. 29). The Fink method accepts gross airframe dimensions such as span, flap chord lengths, and gear configuration and dimensions. The noise reduction technologies applied to the airframe are landing gear fairings, slat cove fillers, and flap porous tips. These technologies are considered mature enough to be available in the 2020 timeframe.

Descriptions of how each of these noise reduction technologies are used and their assumed acoustic benefits are described in detail in (Refs. 4 and 7).

Using an assumption of acoustic superposition, the free-field, lossless spectra for all of the noise sources described above are analytically summed in the vicinity of the aircraft. Real noise sources are, of course, complex, distributed signals that are affected by other acoustic sources, aircraft external surfaces, and the environment. No provisions are made to adjust the component spectra for acoustic near-field phenomena such as source interactions, reflections, refraction, diffraction, or other effects.

The summed spectra are propagated to the three certification observers on the ground in accordance with the specifications for certification measurements. Noise propagation effects accounted for include spherical spreading, Doppler shift and convective amplification, atmospheric attenuation, ground reflections based on data for grass-covered ground, and extra ground attenuation. More complex propagation phenomena such as scattering, weather effects, and terrain are not modeled. The airplane trajectory, computed as described earlier, is fed into the ANOPP simulation. Vector geometry analyses for the airplane relative to the three certification microphone measurement locations are performed within ANOPP as functions of source time. The propagated acoustic spectra are predicted at half-second 
intervals at each of the three certification locations on the ground. From these propagated spectra, ANOPP computes several noise metrics of interest as functions of observer time. The Effective Perceived Noise Level (EPNL) certification noise metric is computed from the noise-time history at each observer as prescribed in (Ref. 2).

In noise certification parlance, the cumulative, or algebraic, sum of the three certification EPNLs is often used to capture the range of operating conditions. The cumulative noise margin with respect to the Stage 4/Chapter 4 regulatory standard is used for the overall noise metric in this paper.

\subsection{Single- and Multi-Objective Optimization}

Single-objective and multi-objective optimal solutions are sought, in various combinations, for block fuel burned, ramp weight, cumulative Stage 4 noise margin, and $\mathrm{LTO}^{\mathrm{NO}} \mathrm{X}_{\mathrm{X}}$ emission objectives.

Single-objective optimal solutions are straightforward. They are obtained using one of the searchstrategy optimizers built into the FLOPS code. In NPSS and WATE, the continuous engine design variable FPR is parametrically varied while permuting each of the two-valued discrete engine design variables. In this manner, several hundred engine designs are computed and passed to FLOPS for singleobjective optimization of the engine size and wing size independent variables. The minimum value of the objective function of interest is chosen by inspection. The objective space is well-behaved; there are never multiple objective peaks and the airplane performance constraints are smooth. The constrained global minima are easily found by examination. Feasibility with respect to each inequality constraint is easily checked. The minima are verified by plotting graphical sizing diagrams for each permutation of the discrete engine design variables. The FLOPS optimizer used is the quasi-Newton Broyden-FletcherGoldfarb-Shanno method along with a Fiacco-McCormick penalty function strategy to account for constraints.

The multi-objective, Pareto-optimal solutions are handled differently. Pareto-optimal solutions are nondominated sets where the value of one objective cannot be improved without punishing another. A set of designs is sought that represent the best possible tradeoffs among the objectives considered. Classical methods of identifying Pareto-optimal solutions are commonly of the "preference" type, where information regarding the relative importance of each objective is assumed a priori by the designer. A scalarization method, for example, often begins by defining a single composite objective using the problem's multiple objective functions. The composite objective is optimized while varying the preferences for each of the underlying objectives until a Pareto solution is computed.

However, this problem has a combination of continuous and discrete design variables. The discrete variables create a mathematically disconnected objective space and constraint functions where gradients are not available to traditional optimizers. In addition, there is unavoidable mathematical "noise" due to the internal iterations and convergence tolerances in the disparate tools that define the objective space (i.e., NPSS, FLOPS, ANOPP, etc.). These problems may confound many search-strategy optimizers by causing them to improperly center over artificial local optima or by making function evaluations discontinuous. This particular problem is also burdened by occasional "nonconverged" points - most commonly in the engine aeromechanical analysis - where the optimizer is left to deal with no information returned from the analysis. It therefore may be difficult to use any classical, composite-objective, scalarization method for this problem. For these reasons, an evolutionary multi-objective algorithm is chosen. The Nondominated, Sorting Genetic Algorithm, NSGA-II (Ref. 30), is selected for its speed (relative to many other evolutionary optimizers) and its ability to control crowding and obtain solution diversity. NSGA-II uses a constrained tournament selection process consisting of crossover and mutation variation operators to define each generation. Binary crossovers involve simple exchanges of genes between parent members, while real-parameter crossovers use a Simulated Binary Crossover method (Ref. 31). In problems involving simultaneous optimization of discrete and continuous variables, the two crossover approaches are combined. Random changes are also introduced in each generation using real and binary mutation operators. The method's no-penalty parameter approach to constraint handling has been shown to achieve convergence while maintaining good population diversity (Ref. 32). 
The use of NSGA-II, or any evolutionary multi-objective algorithm, is not without its disadvantages. Although NSGA-II ranks among the fastest of evolutionary methods, it is still computationally expensive when compared to search-strategy methods; typically requiring about two weeks on a modest platform (an Intel Core 2 Duo (Intel Corporation, Santa Clara, CA)) to run the problems presented here to completion. Potentially, a search-strategy optimizer (set to run a multi-objective optimization for each permutation of the discrete, two-valued design variables) may have led to faster convergence times. Other approaches, such as variable-fidelity meta-modeling, or a simplifying reformulation of the problem statement could also be applied to reduce computational time. NSGA-II is used, however, because it is expected to provide good results, largely without regard for its computational efficiency.

Like search-strategy methods, NSGA-II may also be hampered by nonconverged cases. In a nonconverged case, large numerical values are assigned to each objective function, which has the effect of steering the optimizer away from that area of the design space. These occurrences have the potential to cause difficulties in the NSGA-II child selection process and to slow down the convergence to the Paretooptimal solution.

\subsection{Results and Discussion}

The automated multidisciplinary analysis described above provides objective and constraint function evaluations for the following optimization problems. The objectives are, in various combinations, ramp weight, block fuel burned, cumulative Stage 4 noise margin, and $\mathrm{LTO} \mathrm{NO}_{\mathrm{X}}$ emissions.

\subsection{Minimum Ramp Weight Solution (One Objective)}

The solution for minimum ramp weight is an interesting optimization problem in aircraft design. Minimizing ramp weight is of particular interest because ramp weight is often used as a proxy for vehicle cost. Classical treatments of this problem rarely have included simultaneous optimization of both propulsion system and airframe design variables. Note that, in this context, ramp weight refers to the maximum permissible airplane gross weight "on the ramp" before takeoff. FLOPS determines ramp weight by iterating the design maximum gross weight (and the resulting structural weights, etc.) until the available fuel weight is sufficient to complete the specified design mission.

The problem is formally stated as follows. Mathematical nomenclature similar to that used in Reference 30 is used. The single objective function, $f_{1}$, Equation (1), the independent continuous design variables, $x_{1}$ through $x_{3}$, Equation (2), the discrete design variables, $x_{4}$ through $x_{7}$, Equation (3), and the inequality constraints, $g_{1}$ through $g_{7}$, Equation (4), are written as

$$
\begin{aligned}
& f_{1}=W_{\text {ramp }}(\mathrm{lb}) / 150,000 \\
& x_{1}=S_{W}\left(\mathrm{ft}^{2}\right) / 1400 \\
& x_{2}=F_{N, S L S} \\
& \text { (lb) / 26,000 } \\
& x_{3}=F P R_{A D P} \\
& 0.8 \leq x_{1} \leq 1.6 \\
& 0.8 \leq x_{2} \leq 1.6 \\
& 1.35 \leq x_{3} \leq 1.70 \\
& x_{4}=\text { Fan Drive System } \\
& x_{5}=O P R_{A D P} \\
& x_{4}=\left\{\begin{array}{c}
\text { Direct Drive } \\
\text { Gear Drive }
\end{array}\right. \\
& x_{5}=\left\{\begin{array}{l}
\operatorname{Low}(32) \\
\operatorname{High}(42)
\end{array}\right. \\
& \begin{array}{l}
x_{6}=\text { Low spool } \\
x_{6}=\left\{\begin{array}{l}
\text { Low } \\
\text { High }
\end{array}\right.
\end{array} \\
& x_{7}=\text { Variable Nozzle } \\
& x_{7}=\left\{\begin{array}{l}
\text { True } \\
\text { False }
\end{array}\right.
\end{aligned}
$$




$$
\begin{array}{lll}
g_{1}(\mathbf{x})=\frac{D_{T O}(\mathrm{ft})}{7000}-1 \leq 0 & g_{2}(\mathbf{x})=\frac{D_{L}(\mathrm{ft})}{7000}-1 \leq 0 & g_{3}(\mathbf{x})=\frac{v_{a p p}(\mathrm{kt})}{150}-1 \leq 0 \\
g_{4}(\mathbf{x})=1-\frac{\dot{h}_{\text {pot toc }}(\mathrm{ft} / \mathrm{min})}{300} \leq 0 & g_{5}(\mathbf{x})=\frac{\Delta W_{\text {excess fuel }}(\mathrm{lb})}{10,000} \leq 0 & g_{6}(\mathbf{x})=\frac{\Delta F_{N, s s}(\mathrm{lb})}{1000} \leq 0 \\
g_{7}(\mathbf{x})=\frac{\Delta F_{N, \text { mapp }}(\mathrm{lb})}{1000} \leq 0 &
\end{array}
$$

Note that all objectives, design variables and performance constraints are made dimensionless and are normalized to equivalent orders of magnitude by dividing by appropriate constants. The design variables $x_{1}$ and $x_{2}$ represent wing size and engine size and are the most important variables in a classic airframeengine sizing problem. $x_{3}$ through $x_{7}$ are the propulsion design variables discussed in the previous section. The inequality constraints $g_{1}$ through $g_{7}$ represent typical airplane performance sizing requirements for field length, approach velocity, potential climb rate at top-of-climb (service ceiling) conditions, excess fuel weight (wing fuel capacity), and excess thrust for the second-segment climb and missed approach, respectively. All of the $g_{\mathrm{i}}$ must be non-positive for the solution to be feasible. $g_{1}$ and $g_{2}$ are defined to ensure that field length never exceeds $7000 \mathrm{ft} ; g_{3}$ is defined so that approach airspeed never exceeds $150 \mathrm{kts}$; and $g_{4}$ is defined so that the climb rate at the top of climb never falls short of $300 \mathrm{ft} / \mathrm{min}$ at Mach $0.80,35,000 \mathrm{ft} . g_{5}$ through $g_{7}$ represent "excess" functions for wing fuel capacity and thrust, where values of zero just satisfy the sizing requirement. Note that range is not one of the constraints as the ramp weight is sized to meet the required range independent of the optimization.

A single-objective optimum is easily found by conventional means and does not necessarily require the NSGA-II evolutionary optimizer. Indeed, it is often preferable to perform the optimization using a conventional search-strategy optimizer to more precisely locate the optimum, or to use graphical means to gain insight to the problem. The analysis is performed by running a single-objective constrained optimization of $x_{1}$ and $x_{2}$ in FLOPS (that is, a classical wing and engine sizing) while parametrically changing $x_{3}$ for the sixteen permutations of $x_{4}$ through $x_{7}$ in NPSS and WATE. Solutions are chosen by examination and are confirmed graphically as described in Section 3.6.

The propulsion system representing the minimum ramp weight solution (at 150,800 lb) has a directlydriven fan, a "high" OPR, a "low" work split, and a fixed-geometry bypass nozzle. The ADP FPR is at the maximum value allowed (1.70) for a single-stage fan, which sets the bypass ratio at about 10 . This engine is noted in (Ref. 6) and is shown in Figure 2 (left). The block fuel burned for this design is $31,250 \mathrm{lb}$. Although they are calculated outcomes rather than objectives, its Stage 4 cumulative noise margin and $\mathrm{LTO} \mathrm{NO}_{\mathrm{X}}$ emissions are $-8.4 \mathrm{EPNdB}$ and $25.6 \mathrm{~g} / \mathrm{kN}$, respectively.

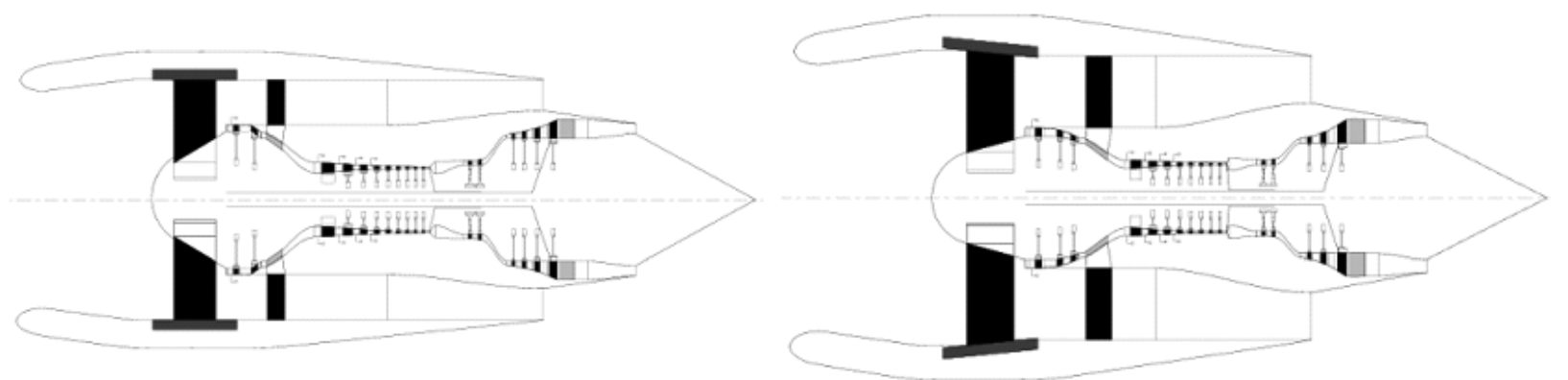

Figure 2.-Turbofan for the minimum ramp weight airplane (left); turbofan for the airplane having the lowest block fuel while minimizing ramp weight (right). 
However, with very little sacrifice in ramp weight, an interesting compromise solution exists that results in the lowest block fuel while minimizing ramp weight. Note this solution differs slightly from the solution presented immediately below, where block fuel is cast as $f_{1}$ in a singleobjective optimization. The compromise solution is discovered by running parametric sweeps in engine designs (i.e., varying $x_{3}$ through $x_{7}$ ) while minimizing ramp weight, and then simply choosing the design having the lowest block fuel. This propulsion system has a gear-driven fan, a "high" OPR, a "high" work split, a fixed-geometry bypass nozzle, and an ADP FPR of 1.48. The FPR is high enough that a variable-geometry bypass nozzle does not appear to be required and its extra weight is not justified. Here, the block fuel is at its lowest $(30,400 \mathrm{lb})$, while the ramp weight $(151,200 \mathrm{lb})$ is only $0.3 \%$ higher than the ramp weight global minimum. The Stage 4 cumulative noise margin and LTO $\mathrm{NO}_{\mathrm{X}}$ emissions are $-21.1 \mathrm{EPNdB}$, and $22.1 \mathrm{~g} / \mathrm{kN}$, respectively. This "compromise solution" engine, shown in Figure 2 (right), is referred to in Reference 6 as perhaps the best balanced engine design when all performance metrics are considered. A graphical sizing diagram for this solution is shown in Figure 3. Ramp weight objective function contours are shown (in klb), and the design solution is shown by the circular marker. Five of the seven inequality constraints $\left(g_{i}\right)$ considered are also plotted, but takeoff field length is the only active (i.e., binding) constraint. Infeasible design space is shaded. When a singleobjective search-strategy optimizer is used, the optimum point may be found quite accurately. Any constraint violation is insignificant.

\subsection{Minimum Block Fuel Solution (One Objective)}

The minimum block fuel weight solution is usually important in finding the minimum cash-direct operating cost design. It is also exactly the same as minimizing block $\mathrm{CO}_{2}$ emissions. The single objective function, $f_{1}$, is written as

$$
f_{1}=W_{\text {blockfuel }}(\mathrm{lb}) / 30,000
$$

The independent design variables, $x_{\mathrm{i}}$, and the inequality constraints, $g_{\mathrm{i}}$, are the same as Equations (2) through (4). The FLOPS optimizer is used as above, with block fuel as the single objective. The propulsion system representing the minimum block fuel solution (at 29,800 lb) has a gear-driven fan, a "high" OPR, a "high" compression work split, and a variable-geometry bypass nozzle. The ADP FPR is 1.36: very nearly at the minimum value allowed (1.35). Ramp weight is $154,900 \mathrm{lb}$; only $3 \%$ higher than the case for minimum ramp weight. The Stage 4 cumulative noise margin and LTO $\mathrm{NO}_{\mathrm{X}}$ emissions are $27.8 \mathrm{EPNdB}$ and $19.2 \mathrm{~g} / \mathrm{kN}$, respectively. The engine diagram is similar in overall architecture and turbomachinery stage counts to the engine shown in Figure 2 (right), so it is not shown here.

It is interesting to note the dramatic differences in engine design for the minimum ramp weight and minimum block fuel cases. The minimum ramp weight design prefers a conventional architecture, lowweight, compact, high-FPR engine, while the minimum block fuel design prefers an alternative, geardriven fan architecture with excellent fuel efficiency, a very low FPR, a high-diameter fan, and a variablegeometry bypass nozzle. This is perhaps to be expected, since a minimum-fuel airplane design should demand the most fuel-efficient engine possible, and would tolerate - to a degree - any reasonable penalties corresponding to such an engine (such as engine weight, diameter, landing gear weight, and nacelle drag penalties). 
With no fan diameter constraint, a FPR of only 1.36 leads to a rather large, 83-inch diameter fan. Very long landing gear are required to provide adequate ground clearance for the engine nacelle. Although changes in gear length and weight are accounted for in this analysis, gear integration and internal wing packaging are not. A more detailed analysis would be required to determine if this engine design could really be accommodated in an underwing configuration.

Also worth noting is that, when considering ramp weight and block fuel objectives, it is always preferable to select the "high" OPR logical design switch. The higher OPR designs (42 at the ADP) have thermal efficiency benefits that are not offset by turbomachinery weight and length penalties.

\subsection{Minimum Block Fuel and Noise Solution (Two Objectives)}

The NSGA-II evolutionary algorithm is used for this two-objective problem. Some initial trial runs helped define the population size to ensure convergence without involving excessive computational effort. With this guidance, the population size is set at 48 members. The objectives are defined as

$$
f_{1}=W_{\text {blockfuel }}(\mathrm{lb}) / 30,000 \quad f_{2}=N M_{\text {Cum }}(\mathrm{EPNdB}) / 25
$$

$f_{2}$ is the Stage 4 cumulative certification noise margin $\left(N M_{C u m}\right)$ normalized to the same order of magnitude as $f_{1}$. The independent design variables, $x_{\mathrm{i}}$, and the inequality constraints, $g_{\mathrm{i}}$, are the same as Equations (2) through (4).

The analysis was stopped after 167 generations (with over 8000 designs analyzed) when it became apparent that the solution was converging exclusively on low-FPR, geared engine designs. This should be expected, since the lowest noise designs and the lowest block fuel designs both occur at very low FPRs. Low-FPR, high-bypass-ratio engine cycles have very little jet noise. And, with the authors' assumption of constant design fan loading, low-FPR cycle designs also have quite low, subsonic fan tip speeds and are thus free of rotor-shock-related fan noise sources. With propulsion noise reduction technologies being equal, the minimum noise solution naturally occurs at the lowest possible FPR values.

Therefore, the simultaneous solution of both objectives focuses on a narrow range of FPR between 1.35 (the minimum allowed) and 1.37. Only a very limited Pareto-optimal solution is possible. In mathematical terms, the cardinality of this Pareto-optimal set is approximately unity.

This is excellent news, since it is widely believed at NASA that meeting our aggressive noise and fuel burn goals simultaneously is not possible. It is for that reason that the NASA Subsonic Fixed Wing Project's goals are often called "corners of the design trade space," where one or two goals may be met simultaneously, but only at the expense of another. These results show that there is not a significant tradeoff between minimizing fuel and minimizing noise when selecting the cycle design characteristics of an engine. Meeting NASA's aggressive goals remains difficult, but low-FPR, geared, UHB turbofans appear to satisfy the requirements of minimizing fuel and minimizing noise.

The Pareto-optimal solution is shown graphically in Figure 4. All feasible solutions encountered during the run of NSGA-II are shown in the chart on the left. The dominated points are retained to illustrate how the optimizer considered, but discarded, direct-drive fan architectures (gray triangles) in favor of geared fans (black diamonds). No direct-drive engines survive the optimizer's selection process that, in this case, favors low-FPR designs. A detailed view of the small, nondominated Pareto front is shown in the chart on the right. Note the change in scale. Propulsion systems with "high OPRs" are shown using open symbols, while systems with "low OPRs" are shown using closed symbols. All of these low-FPR engines along the frontier are geared. No differentiation between "low" or "high" compression work split designs is noticeable after 167 generations, although eventually a preference for one or the other may be expected. The low-OPR engine designs are slightly quieter (the core noise model used is sensitive to compressor exit pressure and temperature), but being less thermally efficient, they consume more fuel. With the clustering in objective space around very low FPRs, the range in block fuel values along the small frontier is less than $1300 \mathrm{lb}$ for the high OPR designs. 

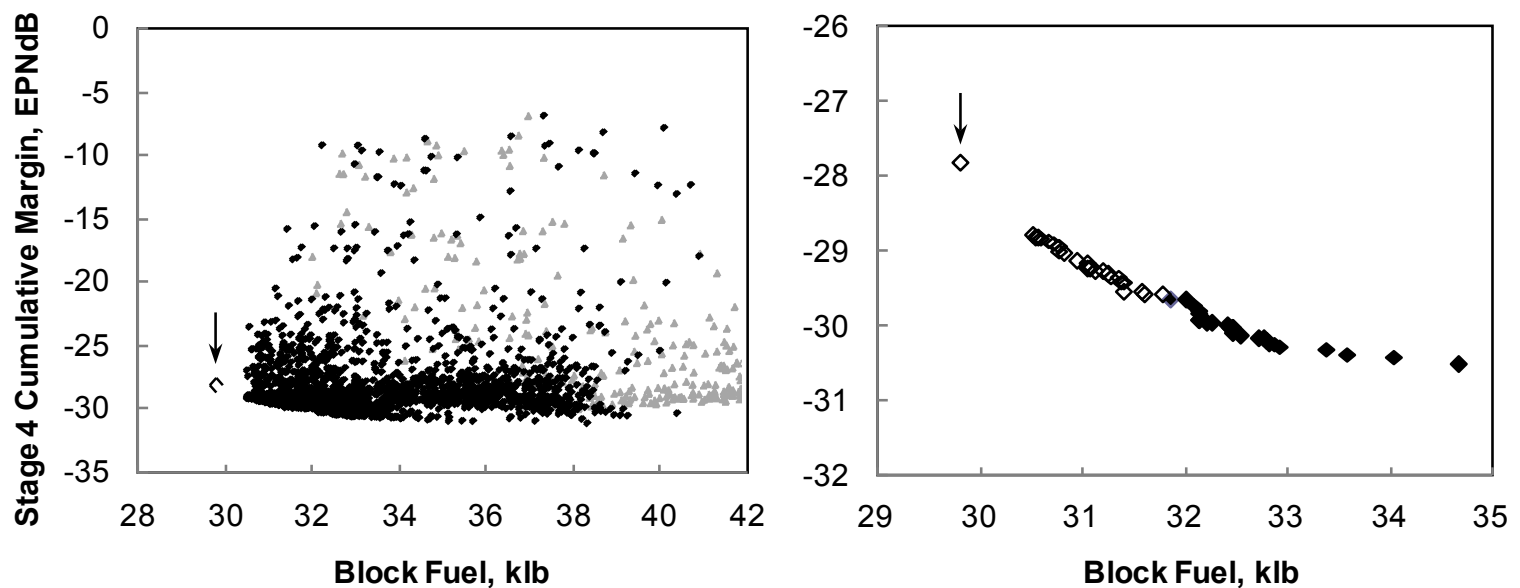

Figure 4.-Pareto-optimal solutions for minimum block fuel and noise. Left: all feasible solutions, showing geared engines (black diamonds) and direct-drive engines (gray triangles); Right: A detailed view of the small, nondominated front, showing high-OPR engines (open symbols) and low-OPR engines (solid symbols). The global block fuel minimum is marked by the arrows.

Note that the minimum block fuel found here $(30,500 \mathrm{lb})$ is not as low as the single-objective minimum found in Section 4.2 (29,800 lb; marked by the arrows in both charts of Fig. 4). An examination of the lowest block fuel nondominated frontier point revealed that it had not yet converged on optimum wing and engine sizes. It is uncertain if the minimum block fuel design of 29,800 lb discovered in Section 4.2 would have been found by the evolutionary algorithm.

The minimum noise margin found by the evolutionary optimizer is $-30.5 \mathrm{EPNdB}$. It is achieved with a very low-FPR, low-OPR, geared fan design.

\subsection{Minimum Ramp Weight and Noise Solution (Two Objectives)}

A much broader Pareto front may be expected for this solution, since the FPR for the global minimum ramp weight (1.70) is far removed from the FPR preferred for minimum noise (1.35). The objectives for this problem are defined as

$$
f_{1}=W_{\text {ramp }}(\mathrm{lb}) / 150,000 \quad f_{2}=N M_{\text {Cum }}(\text { EPNdB }) / 25
$$

As before, the evolutionary algorithm is used with a population size of 48 , and the independent design variables, $x_{\mathrm{i}}$, and the inequality constraints, $g_{\mathrm{i}}$, are the same as Equations (2) through (4).

The analysis was interrupted after 198 generations with 9504 designs analyzed (2628 of them feasible). The Pareto-optimal solution is shown graphically in Figure 5. Once again, all feasible solutions encountered during the run of NSGA-II are shown in the chart on the left, while a more detailed view of the nondominated Pareto front is shown on the right. Note the change in scale.

Once again, the minimum noise margin appears to be approximately $-30.5 \mathrm{EPNdB}$ with an engine design similar to that found above in Section 4.3. The minimum ramp weight of 152,000 lb shown in the Pareto front is achieved with a gear-driven fan system with a FPR of 1.48. This is somewhat unexpected, since, in Section 4.2, the global minimum ramp weight is deterministically found via single-objective optimization to be a direct-drive fan design at 150,800 lb (marked by the downward-pointing arrow in Fig. 5). Several competitive direct-drive engine designs (marked by the gray triangles) can be seen in Figure 5 near 153,000 lb, but they are all dominated by geared engine designs (at least after 198 

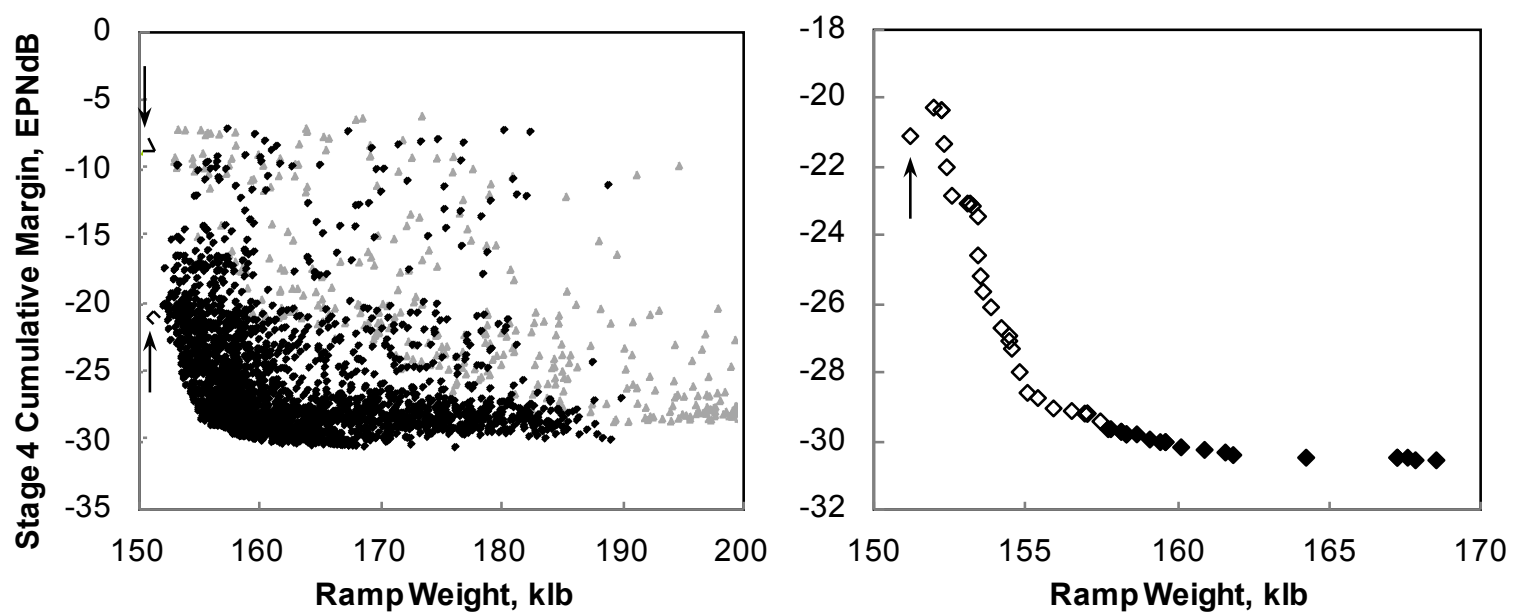

Figure 5.-Pareto-optimal solutions for minimum ramp weight and noise. Left: all feasible solutions, showing geared engines (black diamonds) and direct-drive engines (gray triangles); Right: A detailed view of the nondominated front, showing high-OPR engines (open symbols) and low-OPR engines (solid symbols). The global ramp weight minimum is marked by the downward arrow; the "best compromise" design is marked by the upward arrows.

generations). It is uncertain if the minimum ramp weight, direct-drive design of 150,800 $\mathrm{lb}$ discovered in Section 4.2 would have been found by the evolutionary optimizer. For this problem, a multiple-objective algorithm using a scalarization method to optimize a composite objective with weighting factors may be better suited to finding this part of the frontier.

As it is, however, this evolutionary optimization comes remarkably close to the best "compromise solution" engine design described in Section 4.2 (its ramp weight is 151,200 lb; marked by the upwardpointing arrows in Fig. 5). That design, found deterministically via single-objective optimization, also has a nearly-identical, gear-driven fan design with a FPR of 1.48.

Note the low-noise designs in Figure 5 with ramp weights heavier than 190,000 lb. These are solutions having direct-drive engines with very low FPRs. Although they are feasible solutions, the engines are, of course, very long and heavy, with many LPT stages. The evolutionary optimizer likely discovered these solutions using its crowded comparison operator feature while attempting to extend the frontier towards lower-noise designs. In general, however, most unreasonable engine designs are effectively avoided by the optimizer.

This two-objective optimization clearly shows the trade between ramp weight and noise. Given constant technology levels, improvements in one objective cannot be made without punishing the other. This illustrates the difficulty in designing extremely quiet aircraft, such as those called for by NASA's Subsonic Fixed Wing goals. While it perhaps can be done, it is often uneconomical to do so.

\subsection{Minimum Ramp Weight and $\mathrm{NO}_{\mathrm{X}}$ Solution (Two Objectives)}

Cycles with higher ADP FPRs have higher OPRs at sea level static conditions due to engine specific thrust and thrust lapse characteristics, even if the OPRs at the ADP are designed to be identical. At sea level static conditions (where the LTO $\mathrm{NO}_{\mathrm{X}}$ metrics are measured), cycles having higher ADP FPRs have higher combustor entrance temperatures and pressures and therefore have higher levels of LTO $\mathrm{NO}_{\mathrm{X}}$. Thus, a Pareto front would be expected in a multi-objective optimal solution of ramp weight and LTO $\mathrm{NO}_{\mathrm{X}}$.

This behavior is in contrast to the optimal solution of block fuel and $\mathrm{LTO} \mathrm{NO}_{\mathrm{X}}$, where minima for both of those objectives would tend to cluster around low-FPR engine designs. Since a case of nearly non-conflicting objectives has already been shown (i.e., the minimum block fuel and noise solution in Section 4.3), a minimum block fuel and $\mathrm{LTO} \mathrm{NO}_{\mathrm{X}}$ problem is not presented here. 


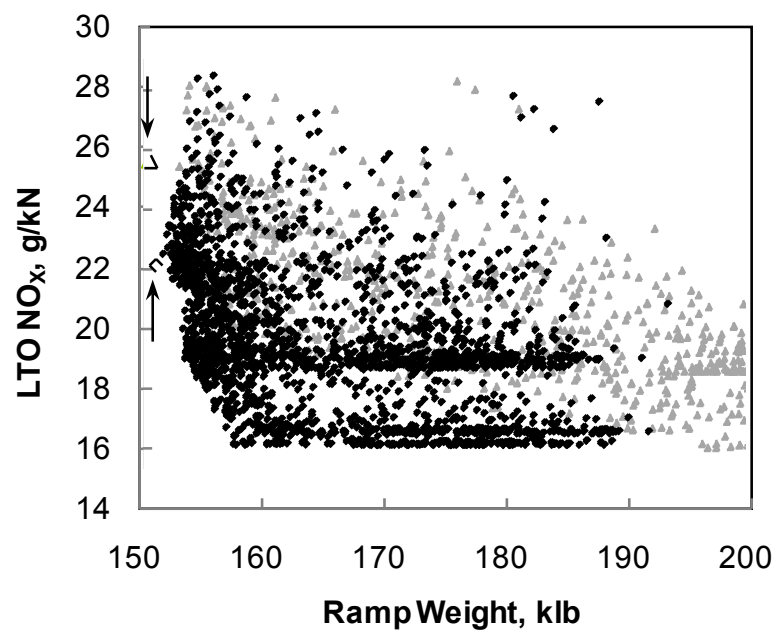

Figure 6.-Pareto-optimal solutions for minimum ramp weight and LTO NOx. All feasible solutions, showing geared engines (black diamonds) and direct-drive engines (gray triangles).

Once again, we note that $\mathrm{LTO} \mathrm{NO}_{\mathrm{X}}$ is an engine-only metric and is entirely independent of any airplane characteristic. It is linked here to ramp weight only by way of our multi-objective system optimization.

The objectives for the minimum ramp weight and $\mathrm{LTO} \mathrm{NO}_{\mathrm{X}}$ problem are defined as

$$
f_{1}=W_{\text {ramp }}(\mathrm{lb}) / 150,000 \quad f_{2}=\operatorname{LTO}_{X}(\mathrm{~g} / \mathrm{kN}) / 20
$$

The same method, design variables, and constraint vector as before are used. The analysis was interrupted after 143 generations with 6864 designs analyzed ( 2773 of them feasible). The Pareto-optimal solution is shown graphically in Figure 6. All feasible designs are shown, with the geared engines plotted using black diamonds and the direct-drive engines using gray triangles.

Once again, the optimizer did not discover the global minimum ramp weight represented by a highFPR, high-OPR, direct-drive engine design (marked by the downward-pointing arrow in the figure), but it did come very close to the compromise design represented by a geared fan design (marked by the upward-pointing arrow). The lower boundaries of the objective space are horizontal and flat because the optimizer found the $\mathrm{NO}_{\mathrm{X}}$ minimum at the limiting 1.35 FPR boundary. As it is, the minimum $\mathrm{LTO} \mathrm{NO}_{\mathrm{X}}$ solution is nearly identical to the minimum noise margin solution found in the previous two sections.

In Figure 6, there are two noticeable groupings, or regimes of engine designs. The high- and low- $\mathrm{NO}_{\mathrm{X}}$ regimes are caused by high- and low-OPR engine cycles, respectively. For combustors of equivalent emissions technology and effectiveness, low-OPR cycles should result in lower LTO NO $\mathrm{N}_{\mathrm{X}}$. There is noticeable symmetry between the low- and high-OPR regimes. That is, one regime has the same general shape as the other, and they are offset in the objective space by the same amounts. Of course, this is an artifact of OPR being represented as a logical design variable; if OPR were a continuous-real variable, two regimes would not be visible and the frontier would not be nonconvex. In any case, the distinct regime behavior permits a generalization: if an engine is designed with a "high" OPR of 42, it should produce approximately $15 \%$ higher LTO $\mathrm{NO}_{\mathrm{X}}$ and have a $1.5 \%$ lower ramp weight than one designed with a "low" OPR of 32, if the engines are otherwise similarly designed. An alternate, and perhaps more appropriate, way to interpret the data is that the high-OPR "best compromise" design (the diamond marked by the upward-pointing arrow) has $36 \%$ higher $\mathrm{NO}_{\mathrm{X}}$ than the lightest, low-OPR, low- $\mathrm{NO}_{\mathrm{X}}$ design $(158 \mathrm{klb}, 16.2 \mathrm{~g} / \mathrm{kN})$. 


\subsection{Engine Design Considerations}

The chief objective in engine design is minimum airplane life cycle cost, while achieving acceptable levels of operational safety, risk, and environmental impact. Vehicle cost is indirectly addressed in this study by predicting its classical surrogate indicator: ramp weight. The block fuel weights predicted are important in finding the minimum cash-direct operating cost design. Safety and risk are much more complex to assess, but they are indirectly recognized here by selecting only technologies mature enough for consideration.

Every attempt has been made in this analysis to provide an unbiased, independent, accurate assessment of aircraft powered by UHB turbofans. Thermodynamic cycle and aeromechanical engine design methods, and even the analytical tools used (NPSS, for example, is a U.S. industry standard) follow engineering state-of-the-practice.

However, the caveat must be stated that the optimal engine designs described here have been found for our analytical model, and not necessarily for the true problem. The engine design approach and technology assumptions used for this study are not exclusive. There are a number of possible variations in the design approach; such as different choices for the ADP (particularly the cruise Mach number), thrust sizing conditions, different cooling philosophies, or a different choice of extraction ratio. Furthermore, our assumptions of future technology levels are speculative. Changes in the technology assumptions and design approach can affect the absolute engine performance and weight, as well as the relative differences among the engine types. All of this together makes our analytical model potentially inexact. The results of this study should be viewed, therefore, in light of the assumptions and approach used. With that reader caution stated, the following engine design recommendations are made.

Higher engine OPR and the resulting thermal efficiency benefits always appear justified for ramp weight and block fuel metrics, despite increases in turbomachinery weight, engine length, and cooling air temperature. The maximum OPR (42) is set in this study by a reasonable compressor exit annular duct height constraint. However, LTO $\mathrm{NO}_{\mathrm{X}}$ emissions are higher for high-OPR engine designs (for given combustor technology levels) due to higher combustor entrance temperature and pressure. There is also a slight increase in core noise for high-OPR engine designs. In advanced UHB engines, core noise may become significant - even at higher throttle settings - since jet and fan noise are lower due to increased bypass ratio, low fan tip speeds, and modern, more effective noise reduction technologies. Accurate core noise modeling for UHB engines is essential. A need is foreseen for improved engine core noise modeling methods at NASA that reflect the high overall pressure ratios of modern engines.

At sufficiently low values of FPR, turbofan engine cycles require some type of variable geometry to avoid fan surge margin problems near sea level and to ensure proper operation throughout the flight envelope. Although it is not the only option, the variable-geometry bypass nozzle appears to be a practical means to enable low-FPR, UHB turbofans.

A summary of each of the optimum solutions is presented in Table 1. The minimum ramp weight and the minimum block fuel weight solutions are the global minima found by the single-objective optimizer in Sections 4.1 and 4.2, respectively. The ramp weight and block fuel "compromise solution" is the design noted in Section 4.1. The minimum noise and the minimum LTO $\mathrm{NO}_{\mathrm{X}}$ solutions are simply designs selected from among the multi-objective cases discussed in Sections 4.3 and 4.5 and may not necessarily be global minima.

TABLE 1.-SUMMARY OF OPTIMUM SOLUTIONS

\begin{tabular}{|l|c|c|c|c|c|c|c|c|c|}
\hline \multicolumn{1}{|c|}{ Description } & FPR & Drive & OPR & $\begin{array}{c}\mathrm{F}_{\mathrm{N}, \mathrm{SLS}} \\
(\mathrm{lb})\end{array}$ & $\begin{array}{c}\mathrm{S}_{\mathrm{W}} \\
\left(\mathrm{ft}^{2}\right)\end{array}$ & $\begin{array}{c}\mathrm{W}_{\text {ramp }} \\
(\mathrm{lb})\end{array}$ & $\begin{array}{c}\mathrm{W}_{\text {block fuel }} \\
(\mathrm{lb})\end{array}$ & $\begin{array}{c}\mathrm{NM}_{\text {Cum }} \\
(\mathrm{EPNdB})\end{array}$ & $\begin{array}{c}\mathrm{LTO}_{\mathrm{NO}} \\
(\mathrm{g} / \mathrm{kN})\end{array}$ \\
\hline Minimum ramp weight & 1.70 & Direct & 42 & 22,650 & 1330 & 150,800 & 31,250 & -8.4 & 25.6 \\
Minimum block fuel & 1.36 & Geared & 42 & 25,000 & 1450 & 154,900 & 29,800 & -27.8 & 19.2 \\
Ramp weight and fuel compromise & 1.48 & Geared & 42 & 23,150 & 1340 & 151,200 & 30,400 & -21.1 & 22.1 \\
Minimum noise & 1.35 & Geared & 32 & 25,100 & 1620 & 164,200 & 33,900 & -30.5 & 16.5 \\
Minimum LTO $\mathrm{NO}_{\mathrm{X}}$ & 1.35 & Geared & 32 & 25,550 & 1430 & 158,700 & 31,900 & -30.3 & 16.2 \\
\hline
\end{tabular}


One of the most important design options considered in this study is the fan drive system. This study is not intended to be an endorsement - or an indictment — of either gear-driven or directly-driven fan designs. Arguments for both engine architectures are given below.

\subsubsection{The Case for Gear-Driven Fans}

The benefits of fuel efficiency that accompany geared turbofans are very attractive. A fan gearbox effectively solves the classical low-spool shaft speed mismatch problem corresponding to low-FPR engine designs. With low FPRs made possible by a geared drive, more enthalpy is available from the LPT that may be used to increase the bypass ratio to ultrahigh levels. A gearbox is thus an enabling technology to dramatic gains in propulsive efficiency.

A gearbox also provides greater freedom in designing the low-pressure compressor, particularly for engines with low-pressure compressors shouldering a greater portion of the overall pressure ratio. Since it rotates rapidly, the low-pressure compressor may have a high pressure ratio with a practical number of stages.

Furthermore, a gearbox appears to justify its additional weight when FPR is sufficiently low. With a gearbox, the LPT need not have a great number of stages when the FPR becomes small, and the fuel efficiency benefits that are inherent in low-FPR, high-bypass-ratio engine cycles pay off dramatically in reduced fuel weight. The best compromise engine design and the minimum block fuel engine design described in Sections 4.1 and 4.2, respectively, are geared engines.

Engines having very low FPRs - geared, typically — are also very quiet, since the bypass ratio increases as FPR decreases. If the bypass ratio is high enough, jet noise becomes a minor contributor to community noise (see Ref. 7). Fan noise is also greatly reduced, particularly if the FPR is low enough to justify subsonic fan tip speeds at takeoff and all shock-related fan noise sources vanish. And as it has been shown in Section 4.5, low-FPR engine cycles can also be low in LTO $\mathrm{NO}_{\mathrm{X}}$ emissions (for combustors of equivalent emissions technology and effectiveness).

The gearbox extends the range of viable FPRs to lower levels and effectively widens the engine cycle design space. If engine size and integration issues can be overcome, geared turbofans have the potential to extend the bypass ratio into the UHB range.

\subsubsection{The Case for Directly-Driven Fans}

Despite the apparent advantages of geared turbofans, direct-drive turbofans remain a good design choice. Direct-drive turbofans result in the lowest engine weight, vehicle ramp weight, and operating empty weight, and, by inference, the lowest vehicle cost.

Engines having higher FPRs - directly-driven, typically — can have relatively small, compact nacelles with less wetted area and drag than higher-diameter geared engines. They also simplify landing gear design. Although the effects of landing gear length and weight are accounted for in this study, the impacts of gear integration, retraction, and internal wing packaging are not. Likewise, the aerodynamic effects of high-diameter engines are accounted for here, but only to the first-order. A higher-fidelity modeling of high-diameter geared engine issues is called for, such as nacelle-wing interference drag effects and engine-out drag and its impact on tail sizing. Moreover, no gearbox maintenance is necessary for directdrive turbofans.

Furthermore, a large portion of the direct-drive turbofan design space remains unexplored in this study. Constant design fan loading is assumed here - that is, as FPR is reduced, fan tip speed is reduced as well. The classical low-spool shaft speed mismatch problems associated with lower-FPR, direct-drive engines can be alleviated somewhat by using lightly-loaded fans. More fuel-efficient, direct-drive engines having moderately lower FPRs and higher bypass ratios may have been discovered in this assessment if fan loading was treated as a design variable. Also, and perhaps counterintuitively, lower burner temperatures may lead to better direct-drive engines. Lowering the gas temperature lowers the speed of sound in the hot section and can mitigate the shaft speed mismatch by effectively increasing the LPT tip Mach numbers. Turbine cooling and hot section material benefits may exist as well. Attractive, lowertemperature, direct-drive engine designs with lightly-loaded fans may exist throughout the design space. 


\subsection{Conclusions}

Single- and multi-objective optimized solutions are presented for the multidisciplinary design of ultrahigh bypass ratio engines applied to an advanced, notional, single-aisle airplane. NASA's Subsonic Fixed Wing Project goals serve as optimization objectives. This study is intended to provide independent information to NASA program management to help guide its technology development efforts.

Identifying a "best" engine design depends entirely on the metric(s) of interest. The engine design for minimum ramp weight — a traditional aircraft optimization objective - is found to be a high-FPR, highOPR, direct-drive turbofan. Although its turbomachinery, material selection, cooling, and construction technologies are assumed to be advanced, it may yet be said to be of a conventional architecture. Block fuel, however, is minimized by a strikingly different engine design: a low-FPR, high-OPR, geared UHB turbofan with a variable-geometry bypass nozzle. And between these two extremes, an excellent "compromise" engine design exists - a moderate-FPR, high-OPR, geared turbofan - that nicely balances the ramp weight and block fuel metrics. This engine also has relatively low community noise and $\mathrm{NO}_{\mathrm{X}}$ emissions.

An interesting finding is how, when multiple objectives are considered, some metrics may be improved upon simultaneously. It is widely believed at NASA that meeting our aggressive noise and fuel burn goals simultaneously is not possible. However, block fuel and noise appear to be minimized together by selecting similar engine cycle design characteristics (i.e., low-FPR, geared, UHB turbofans). $\mathrm{NO}_{\mathrm{X}}$ exhaust emissions are minimized by low-FPR, geared designs as well, although $\mathrm{NO}_{\mathrm{x}}$ is minimized more dramatically by lowering OPR. Other metrics, when taken together as multiple objectives, form classical Pareto frontiers, where one metric cannot be improved without punishing another. Optimization has the potential to discover many engine designs that acceptably satisfy multiple objectives. The choice of optimization algorithm, the problem analysis fidelity and formulation are key considerations when performing this type of analysis.

Ultimately the primary metric is life cycle cost, while achieving acceptable levels of environmental impact and achieving operational safety. Historically, ramp weight has been used as a surrogate indicator for life cycle cost in aircraft design and optimization. However, recent increases in fuel cost have made fuel consumption a more important factor in the calculation of life cycle cost. It may no longer be valid to assume the lowest ramp weight configuration has the lowest life cycle cost.

\section{References}

1. International Civil Aviation Organization; Report of the Committee on Aviation Environmental Protection, Sixth Meeting, Montreal, February 2-12, 2004 (Doc 9836, CAEP/6).

2. U.S. Code of Federal Regulations, Title 14, Chapter I, Part 36, Noise standards: Aircraft Type and Airworthiness Certification.

3. International Standards and Recommended Practices-Environmental Protection, Annex 16 to the Convention on International Civil Aviation, Volume I: Aircraft Noise, 3rd Edition, International Civil Aviation Organization (ICAO), Montreal, Canada, July 2008.

4. Guynn, M. D., Berton, J. J., Fisher, K. L., Haller, W. J., Tong, M. T., and Thurman, D. R., "Engine Concept Study for an Advanced Single-Aisle Transport," NASA TM-2009-215784, August 2009.

5. Guynn, M. D., Berton, J. J., Fisher, K. L., Haller, W. J., Tong, M. T., and Thurman, D. R., “Analysis of Turbofan Design Options for an Advanced Single-Aisle Transport Aircraft," AIAA Paper 20096942, Sept. 2009.

6. Guynn, M. D., Berton, J. J., Fisher, K. L., Haller, W. J., Tong, M. T., and Thurman, D. R., "Refined Exploration of Turbofan Design Options for an Advanced Single-Aisle Transport," NASA TM2011-216883, Jan. 2011.

7. Berton, J., Envia, E., and Burley, C., "An Analytical Assessment of NASA's N+1 Subsonic Fixed Wing Project Noise Goal,” AIAA Paper 2009-3144, May 2009. 
8. Claus, R. W., Evans, A. L., Lytle, J. K., and Nichols, L. D., "Numerical Propulsion System Simulation," Computing Systems in Engineering, Vol. 2, 1991, No. 4, pp. 357-364.

9. NPSS, Numerical Propulsion System Simulation, Software Package, Ver. 1.6.5, NASA, 2008.

10. Onat, E., and Klees, G., "A Method to Estimate Weight and Dimensions of Large and Small Gas Turbine Engines,” NASA CR-159481, 1979.

11. McCullers, L. A., "Aircraft Configuration Optimization Including Optimized Flight Profiles," NASA CP-2327, April 1984, pp. 396-412.

12. Ardema, M. D., Chambers, M. C., Patron, A. P., Hahn, A. S., Miura, H., and Moore, M. D., "Analytical Fuselage and Wing Weight Estimation of Transport Aircraft," NASA TM-110392, May 1996.

13. U.S. Code of Federal Regulations, Title 14, Chapter I, Part 25, Airworthiness Standards: Transport Category Airplanes.

14. “737 Airplane Characteristics for Airport Planning," Boeing Commercial Airplanes, D6-58325-6, Oct. 2005.

15. International Standards and Recommended Practices-Environmental Protection, Annex 16 to the Convention on International Civil Aviation, Volume II: Aircraft Engine Emissions, 2nd Edition, International Civil Aviation Organization (ICAO), Montreal, Canada, July 1993.

16. U.S. Code of Federal Regulations, Title 14, Chapter I, Part 34, Fuel Venting and Exhaust Emission Requirements for Turbine Engine-Powered Airplanes.

17. Rink, K. K., and Lefebvre, A. H., "The Influence of Fuel Composition and Spray Characteristics on Nitric Oxide Formation," Combustion, Science and Technology, Vol. 68, 1989, pp. 1-14.

18. Correa, S. M., "Lean Premixed Combustion for Gas Turbines: Review and Required Research," Fossil Fuel Combustion, ASME PD, Vol. 33, 1991.

19. Leonard, G. L., and Correa, S. M., "NOX Formation in Lean Premixed High-Pressure Methane Flames," Second ASME Fossil Fuel Combustion Symposium, PD-30, 1990, pp. 69-74.

20. Dahl, M.D. (ed.), “Assessment of NASA's Aircraft Noise Prediction Capability," NASA TP-2011215653 (to be published, 2011).

21. Gillian, R. E., "Aircraft Noise Prediction Program User's Manual,” NASA TM-84486, 1983.

22. Zorumski, W. E., "Aircraft Noise Prediction Program Theoretical Manual, Parts 1 and 2," NASA TM-83199, 1981.

23. Kontos, K. B., Janardan, B., and Gliebe, P. R., "Improved NASA-ANOPP Noise Prediction Computer Code for Advanced Subsonic Propulsion Systems Volume 1: ANOPP Evaluation and Fan Noise Model Improvement," NASA CR-195480, 1996.

24. Stone, J. R., Krejsa, E. A., Clark, B. J., and Berton, J. J., "Jet Noise Modeling for Suppressed and Unsuppressed Aircraft in Simulated Flight," NASA TM-2009-215524, 2009.

25. Emmerling, J. J.; Kazin, S. B.; and Matta, R. K., "Core Engine Noise Control Program. Volume III, Supplement 1-Prediction Methods," FAA-RD-74-125, III-I, Mar. 1976.

26. Ho, P. Y., and Doyle, V. L., "Combustion Noise Prediction Update," AIAA Paper 1979-0588, 1979.

27. Jones, M., Parrott, T., Sutliff, D., Hughes, C., "Assessment of Soft Vane and Metal Foam Engine Noise Reduction Concepts," AIAA Paper 2009-3142, 2009.

28. Sutliff, D. L., Jones, M. G., and Hartley, T. C., "Attenuation of FJ44 Turbofan Engine Noise with a Foam-Metal Liner Installed Over-the-Rotor," AIAA Paper 2009-3141, 2009.

29. Fink, M. R., “Airframe Noise Prediction Method," FAA-RD-77-29, March, 1977.

30. Deb, K., Pratap, A., Agarwal, S., and Meyarivan, T., "A Fast and Elitist Multi-Objective Genetic Algorithm: NSGA-II,” IEEE Transactions on Evolutionary Computation, Vol. 6, No. 2, 2002, pp. 181-197.

31. Deb, K., and Agrawal, R. B., "Simulated Binary Crossover for Continuous Search Space," Complex Systems, Vol. 9, No. 2, 1995, pp. 115-148.

32. Deb, K., Pratap, A., and Meyarivan, T., "Constrained Test Problems for Multi-objective Evolutionary Optimization," Proceedings of the First International Conference on Evolutionary Multi-Criterion Optimization, March 2001, pp. 284-298. 


\begin{tabular}{|c|c|c|c|c|c|}
\hline \multicolumn{5}{|c|}{ REPORT DOCUMENTATION PAGE } & $\begin{array}{c}\text { Form Approved } \\
\text { OMB No. 0704-0188 }\end{array}$ \\
\hline \multicolumn{6}{|c|}{$\begin{array}{l}\text { The public reporting burden for this collection of information is estimated to average } 1 \text { hour per response, including the time for reviewing instructions, searching existing data sources, gathering and maintaining the } \\
\text { data needed, and completing and reviewing the collection of information. Send comments regarding this burden estimate or any other aspect of this collection of information, including suggestions for reducing this } \\
\text { burden, to Department of Defense, Washington Headquarters Services, Directorate for Information Operations and Reports (0704-0188,), } 1215 \text { Jefferson Davis Highway, Suite } 1224 \text {, Allington, VA } 222202-40202 \text {. } \\
\text { Respondents should be aware that notwithstanding any other provision of law, no person shall be subject to any penalty for failing to comply with a collection of information if it does not display a currently valid OMB } \\
\text { control number. } \\
\text { PLEASE DO NOT RETURN YOUR FORM TO THE ABOVE ADDRESS. }\end{array}$} \\
\hline \multicolumn{2}{|c|}{$\begin{array}{l}\text { 1. REPORT DATE (DD-MM-YYYY) } \\
01-04-2012\end{array}$} & \multicolumn{3}{|c|}{$\begin{array}{l}\text { 2. REPORT TYPE } \\
\text { Technical Memorandum }\end{array}$} & 3. DATES COVERED (From - To) \\
\hline \multirow{3}{*}{\multicolumn{5}{|c|}{$\begin{array}{l}\text { 4. TITLE AND SUBTITLE } \\
\text { Multi-Objective Optimization of a Turbofan for an Advanced, Single-Aisle Transport }\end{array}$}} & 5a. CONTRACT NUMBER \\
\hline & & & & & 5b. GRANT NUMBER \\
\hline & & & & & 5c. PROGRAM ELEMENT NUMBER \\
\hline \multirow{3}{*}{\multicolumn{5}{|c|}{$\begin{array}{l}\text { 6. AUTHOR(S) } \\
\text { Berton, Jeffrey, J.; Guynn, Mark, D. }\end{array}$}} & 5d. PROJECT NUMBER \\
\hline & & & & & 5e. TASK NUMBER \\
\hline & & & & & $\begin{array}{l}\text { 5f. WORK UNIT NUMBER } \\
\text { WBS 561581.02.08.03.13.03 }\end{array}$ \\
\hline \multicolumn{5}{|c|}{$\begin{array}{l}\text { 7. PERFORMING ORGANIZATION NAME(S) AND ADDRESS(ES) } \\
\text { National Aeronautics and Space Administration } \\
\text { John H. Glenn Research Center at Lewis Field } \\
\text { Cleveland, Ohio 44135-3191 }\end{array}$} & $\begin{array}{l}\text { 8. PERFORMING ORGANIZATION } \\
\text { REPORT NUMBER } \\
\text { E-18118 }\end{array}$ \\
\hline \multirow{2}{*}{\multicolumn{5}{|c|}{$\begin{array}{l}\text { 9. SPONSORING/MONITORING AGENCY NAME(S) AND ADDRESS(ES) } \\
\text { National Aeronautics and Space Administration } \\
\text { Washington, DC 20546-0001 }\end{array}$}} & $\begin{array}{l}\text { 10. SPONSORING/MONITOR'S } \\
\text { ACRONYM(S) } \\
\text { NASA }\end{array}$ \\
\hline & & & & & $\begin{array}{l}\text { 11. SPONSORING/MONITORING } \\
\text { REPORT NUMBER } \\
\text { NASA/TM-2012-217428 }\end{array}$ \\
\hline \multicolumn{6}{|c|}{$\begin{array}{l}\text { 12. DISTRIBUTION/AVAILABILITY STATEMENT } \\
\text { Unclassified-Unlimited } \\
\text { Subject Categories: } 5,7 \text {, and } 64 \\
\text { Available electronically at http://www.sti.nasa.gov } \\
\text { This publication is available from the NASA Center for AeroSpace Information, 443-757-5802 }\end{array}$} \\
\hline \multicolumn{6}{|c|}{$\begin{array}{l}\text { 13. SUPPLEMENTARY NOTES } \\
\text { Submitted to the AIAA Journal of Aircraft. }\end{array}$} \\
\hline \multicolumn{6}{|c|}{$\begin{array}{l}\text { 14. ABSTRACT } \\
\text { Considerable interest surrounds the design of the next generation of single-aisle commercial transports in the Boeing } 737 \text { and Airbus A320 } \\
\text { class. Aircraft designers will depend on advanced, next-generation turbofan engines to power these airplanes. The focus of this study is to } \\
\text { apply single- and multi-objective optimization algorithms to the conceptual design of ultrahigh bypass turbofan engines for this class of } \\
\text { aircraft, using NASA's Subsonic Fixed Wing Project metrics as multidisciplinary objectives for optimization. The independent design } \\
\text { variables investigated include three continuous variables: sea level static thrust, wing reference area, and aerodynamic design point fan } \\
\text { pressure ratio, and four discrete variables: overall pressure ratio, fan drive system architecture (i.e., direct- or gear-driven), bypass nozzle } \\
\text { architecture (i.e., fixed- or variable geometry), and the high- and low-pressure compressor work split. Ramp weight, fuel burn, noise, and } \\
\text { emissions are the parameters treated as dependent objective functions. These optimized solutions provide insight to the ultrahigh bypass } \\
\text { engine design process and provide information to NASA program management to help guide its technology development efforts. }\end{array}$} \\
\hline \multicolumn{6}{|c|}{$\begin{array}{l}\text { 15. SUBJECT TERMS } \\
\text { Aircraft engines; Aircraft design; Aircraft noise; Exhaust emission; Multidisciplinary design optimization }\end{array}$} \\
\hline \multicolumn{3}{|c|}{ 16. SECURITY CLASSIFICATION OF: } & $\begin{array}{l}\text { 17. LIMITATION OF } \\
\text { ABSTRACT }\end{array}$ & $\begin{array}{l}\text { 18. NUMBER } \\
\text { OF }\end{array}$ & $\begin{array}{l}\text { 19a. NAME OF RESPONSIBLE PERSON } \\
\text { STI Help Desk (email:help@sti.nasa.gov) }\end{array}$ \\
\hline $\begin{array}{l}\text { a. REPORT } \\
\text { U }\end{array}$ & $\begin{array}{l}\text { b. ABSTRACT } \\
\mathrm{U}\end{array}$ & $\begin{array}{l}\text { c. THIS } \\
\text { PAGE } \\
\text { U }\end{array}$ & UU & $\begin{array}{l}\text { PAGES } \\
26\end{array}$ & $\begin{array}{l}\text { 19b. TELEPHONE NUMBER (include area code) } \\
443-757-5802\end{array}$ \\
\hline
\end{tabular}


